\title{
Thyroglobulin/thyrotropin ratio for predicting long-term response in differentiated thyroid carcinoma: a retrospective study
}

1 Departamento de Clínica Médica, Faculdade de Medicina de Botucatu, Universidade Estadual Paulista (Unesp), Botucatu, SP, Brasil 2 Departamento de Oftalmologia, Otorrinolaringologia e Cirurgia de Cabeça e Pescoço, Faculdade de Medicina de Botucatu Universidade Estadual Paulista (Unesp), Botucatu, SP, Brasil

${ }^{3}$ Departamento de Patologia, Faculdade de Medicina de Botucatu, Universidade Estadual Paulista (Unesp), Botucatu, SP, Brasil

${ }^{4}$ Departamento de Medicina Nuclear, Faculdade de Medicina de Botucatu, Universidade Estadual Paulista (Unesp), Botucatu, SP, Brasil

Correspondence to:

Gláucia Maria Ferreira da Silva Mazeto Departamento de Clínica Médica, Faculdade de Medicina de Botucatu, Universidade Estadual Paulista (Unesp)

Av. Prof. Mário Rubens Guimarães Montenegro, s/n

18618-970 - Botucatu, SP, Brasil g.mazeto@unesp.br

Received on Jan/21/202 Accepted on Apr/26/202

DOI: $10.20945 / 2359-3997000000387$
Adriano Francisco De Marchi Junior ${ }^{1}$

https://orcid. org/0000-0001-9939-3569

Ana Bárbara Trizzotti de Macedo'

https://orcid.org/0000-0002-2334-1639

Carlos Segundo Paiva Soares ${ }^{2}$

https://orcid. org/0000-0003-0121-9533

Fernanda Bolfi ${ }^{1}$

https://orcid.org/0000-0002-1444-592X

Mariana Riello Gomes lessi ${ }^{1}$

https://orcid.org/0000-0002-9235-5209

Cristiano Claudino de Oliveira ${ }^{3}$

https://orcid.org/0000-0001-6682-5230

Katia Hiromoto Koga ${ }^{4}$

https://orcid.org/0000-0001-6223-7263

Sonia Marta Moriguchi ${ }^{4}$

https://orcid.org/0000-0001-5834-2714

José Vicente Tagliarini²

https://orcid.org/0000-0002-0869-724X

Gláucia Maria Ferreira da Silva Mazeto'

https://orcid.org/0000-0003-2129-7256

\begin{abstract}
Objective: Thyrotropin-stimulated thyroglobulin (STg) after total thyroidectomy is a prognosis marker for differentiated thyroid carcinoma (DTC). As Tg level is influenced by thyrotropin (TSH), perhaps the $\mathrm{STg} / \mathrm{TSH}$ ratio is also a prognosis marker for these tumours. We aimed to compare STg/TSH ratio and first STg level in differentiated thyroid carcinoma patients for their ability to predict the long-term response to initial treatment. Subjects and methods: This retrospective study evaluated data from 181 DTC patients for first (1st) STg and STg/TSH ratio, at 1-3 months post-total thyroidectomy and before iodine-131 therapy, according to response to initial therapy [Excellent/Indeterminate or Incomplete (Biochemical/Structural)] observed at final evaluation, and with the survival time with excellent/ indeterminate response. Results: Cases with incomplete response presented higher STg level [225.13 $\pm 585.26 \mathrm{ng} / \mathrm{mL}$ versus $(v s) 20.4 \pm 192.9 \mathrm{ng} / \mathrm{mL} ; \mathrm{p}<0.001]$ and STg/TSH ratio (3.01 \pm 7.8 vs $0.27 \pm 2.58 ; \mathrm{p}$ $<0.001$ ). Cutoffs of $5 \mathrm{ng} / \mathrm{mL}$ for STg and 0.085 for STg/TSH displayed sensitivities of $76.7 \%$ and $76.9 \%$, and specificities of $79.2 \%$ and $82.6 \%$, respectively, in predicting response to therapy. Values below these cutoffs were associated with longer survival time in excellent/indeterminate response (140.4 vs 15.9 and 144.6 vs 15.9 months, respectively). Conclusion: STg/TSH ratio has a similar performance to the $1^{\text {st }}$ STg in predicting long-term response to initial therapy. Arch Endocrinol Metab. 2021;65(4):428-35

Keywords

Thyroid neoplasms; thyroglobulin; prognosis
\end{abstract}

\section{INTRODUCTION}

$\mathrm{D}$ ifferentiated thyroid carcinomas (DTC) make up almost all malignant thyroid neoplasias and have been increasing in incidence (1). The most frequent DTC's are papillary carcinomas (PC) accounting for more than $80 \%$ of cases with follicular carcinomas (FC) corresponding to between 10 and $13 \%(2,3)$.
DTC's have low lethality rates and slow indolent growth. Although 10 year survival rates are around $80 \%-95 \%$, some cases have more aggressive behaviour and recurrence levels up to $35 \%$ indicating a cautious approach and long-term clinical follow-up (4-8). For a long time the standard treatment for these tumours was total thyroidectomy (TT) followed by iodine-131 
$\left.{ }^{131} \mathrm{I}\right)$ therapy and thyrotropin (TSH) suppression with levothyroxine (2). More recently, more conservative surgical therapies have been proposed along with less rigorous follow-up strategies depending on tumour presentation and behaviour, and case evolution expectations (2).

Thus, efforts have been made to detect early markers of patient evolution in order to better control the need for additional treatment to thyroidectomy and more rigorous long-term follow-up. Several individual factors have been reported as prognosis indicators; these include patient age and lymph node involvement (5). Additionally, staging systems applied after initial treatment have been used for this purpose, the most common being from the American Joint Committee on Cancer (AJCC/TNM) (2). As this system evaluates the risk of death from neoplasia, and as mentioned above, DTC is characterised by its low mortality rates, the American Thyroid Association (ATA) proposed a recurrence risk stratification system, classifying cases as low, intermediate or high risk (2). Although this system is very useful, it does not evaluate long-term case evolution according to treatment given. Thus, the latest ATA guidelines suggest a new more dynamic classification system based on therapeutic response to initial treatment (2).

Although all these systems have useful proven tools in evaluating risk of death and recurrence, they do present some complexity as many factors need to be assessed. It would therefore be very interesting if there was a unique marker which could be used at the start of follow-up to predict which patients need more aggressive treatment. In this context emerges the role of measuring thyroglobulin ( $\mathrm{Tg}$ ) serum level which has already been demonstrated as a prognosis predictor in DTC (9-12). Its levels, straight after initial treatment, can help determine the presence of persistent or recurrent disease and represent an independent prognosis factor for treatment success (11).

After TT, Tg seems to reach its lowest level at around three to four weeks (2), and its levels are influenced by various factors, including the presence of anti- $\mathrm{Tg}$ antibodies $(\mathrm{TgAb})(6,13,14)$, the remaining quantity of thyroid tissue, the presence of metastatic lesion, time since surgery, and characteristics inherent to the test used for taking measurements $(2,15)$. Also, TSH level at the time of $\mathrm{Tg}$ measurement could have an impact on marker concentration $(2,15)$. In fact, although that both basal $\mathrm{Tg}$ (during levothyroxine treatment) and stimulated Tg (by high TSH levels; STg) can be used
(2), in about $20 \%$ of patients with undetectable basal $\mathrm{Tg}$, the marker is elevated when TSH is higher, which could indicate a worse prognosis $(16,17)$. Thus, STg, obtained both with endogenous TSH and with recombinant TSH use, could be more sensitive than basal $\mathrm{Tg}$ (17).

To measure STg under stimulation with endogenous $\mathrm{TSH}$, it is generally necessary to suspend levothyroxine for three to four weeks, aiming at a significant increase in TSH. Unfortunately, the ideal TSH level to stimulate $\mathrm{Tg}$ production by the remaining thyroid/neoplastic cells has not yet been fully established. Concentrations above $30 \mathrm{mU} / \mathrm{L}$ seem to be necessary, however, levels between 60 and $90 \mathrm{mU} / \mathrm{L}$ would be more reliable for evaluating the marker (18). It is also difficult to compare different STg measurements and the marker level evolution considering the possibility that TSH concentration may be different in each sample. For example, would the same STg values obtained with TSH levels of 31 or $90 \mathrm{mU} / \mathrm{L}$ have the same meaning? In this sense, considering pituitary hormone level, the STg/TSH ratio could have a greater potential for comparison and be a better predictor of therapeutic success than the isolated STg level. The STg/TSH ratio has already proved to be a reliable marker in predicting ${ }^{131}$ I ablative/therapeutic success (11). In fact, when obtained in the pre-ablative period, this ratio seems valuable in predicting both the ablative success (19), and the presence of metastases (15). No references were found on using the $\mathrm{STg} / \mathrm{TSH}$ ratio to assess longterm case evolution. Thus, this study aimed to compare $\mathrm{STg} / \mathrm{TSH}$ ratio and first STg level in their ability to predict long-term response to initial therapy.

\section{SUBJECTS AND METHODS}

This study was approved by the Botucatu Medical School Ethics Committee (CAAE no. 83473918.6.0000.5411; Reference no. 2.532.645). This retrospective study compared STg/TSH ratio and first post-thyroidectomy STg level ( $1^{\text {st }} S T g$ ) for capacity to predict therapeutic response in DTC patients at final evaluation and during follow-up using classification from the latest ATA guidelines (2). Data were collected from medical records of DTC patients evaluated in a tertiary hospital.

\section{Patients}

We evaluated 278 DTC patients followed at a specialised out-patient clinic and selected 181 cases $(65.1 \%)$ according to the following criteria. Inclusion criteria 
were: cases with anatomopathological DTC diagnosis, submitted to this service's standardised initial treatment between 2001 and 2015 (the period where a standard Tg measuring method was maintained), which at that time consisted of TT followed by ${ }^{131}$ I therapy (DTI); who had $\mathrm{Tg}, \mathrm{TgAb}$ and $\mathrm{TSH}$ results evaluated 1 to 3 months after TT and before DTI; and who had had clinical, laboratory, cervical ultrasound exam follow-up for at least 24 months after initial treatment. Exclusion criteria were: patients who presented positive $\mathrm{TgAb}$; and those with TSH and Tg levels measured from different samples and by different methodologies.

\section{Variables of interest and evaluated outcomes}

The main variables of interest in this study were $1^{\text {st }}$ STg concentrations evaluated between 1 to 3 months post-TT but before DTI, and the ratio between $1^{\text {st }}$ STg and TSH (STg/TSH). Evaluated outcomes were response to treatment at final evaluation and survival time maintained in excellent/indeterminate response. Response to therapy was assessed according to latest ATA therapy response guidelines: excellent, biochemical incomplete, structural incomplete, and indeterminate response (2). According to this classification, patients were categorised as excellent/ indeterminate response or incomplete (biochemical and/or structural) response.

The following patient data were also collected: gender; referred race, white or non-white; age a diagnosis in years; neck dissection performed; anatomopathological diagnosis, according to previous recommendations (20); staging with regard to risk of death, according to AJCC/TNM $7^{\text {th }}$ edition classification system (21); and with regard to ATA predicted risk of recurrence (low, intermediate, or high) (2); result of $1^{\text {st }}$ whole body scan (WBS; considered positive when with cervical or distant uptake after administration of a ${ }^{131}$ I tracing dose), total accumulated therapeutic ${ }^{131} \mathrm{I}$ dose; response to therapy $\mathrm{l}$ year after initial treatment, and follow-up time in months.

\section{Methods}

Treatment and follow-up of DTC patients was performed during the data collection period for this study, as previously reported (11). Briefly, this included TT, reassessment 1 to 3 months after surgery with STg measured by endogenous TSH ( $1^{\text {st }}$ STg), WBS, and neck ultrasound (US). Patients subsequently received DTI and were submitted to post-dose WBS about 5 days after treatment. A new evaluation was performed l year after DTI with diagnostic WBS, cervical US, and STg and TSH levels. During follow-up, patients were re-evaluated every four to six months with clinical examination and measurements of free thyroxin (FT4), $\mathrm{TSH}, \mathrm{Tg}$ and $\mathrm{TgAb}$, as well as annual neck ultrasound. If findings suggested persistent or recurrent disease, other imaging tests such as computed tomography, magnetic resonance and positron emission computed tomography (PET-CT) were requested, and if necessary cytohistological exams.

Measurements of FT4, TSH and $\mathrm{Tg}$ were performed the Service's Clinical Laboratory using chemiluminescence (DPC, Los Angeles, CA, USA), with the following reference values $(\mathrm{RV})$ : $0.80-1.90$ $\mathrm{ng} / \mathrm{dL}, 0.40-4.0 \mu \mathrm{IU} / \mathrm{mL}$ and $0.83-68.0 \mathrm{ng} / \mathrm{mL}$, respectively. Analytical Tg sensitivity was $0.2 \mathrm{ng} / \mathrm{mL}$, while functional sensitivity was $0.9 \mathrm{ng} / \mathrm{mL}$ (for levels higher than $2 \mathrm{ng} / \mathrm{mL}$ ). TgAb was measured at the same laboratory by chemiluminescence (Immulite 2000, Siemens, Llanberis, Gwynedd, United Kingdom), with manufacturer $\mathrm{RV}$ of $\leq 40 \mathrm{UI} / \mathrm{mL}$, above which it was considered positive.

\section{Statistical analysis}

Collected data were tabulated in Excel $^{\circledR}$ (Microsoft Corporation, USA) and submitted to statistical analysis using SAS v9.4 software. Qualitative variables were expressed as frequencies and percentages and evaluated using the Chi-squared and Fisher Exact tests. Quantitative variables were expressed and means and standard deviations and evaluated by the Student $t$ test. In general, a $5 \%(\mathrm{p}<0.05)$ significance level was adopted. However, variables with $\mathrm{p} \leq 0.15$ were submitted to multivariate logistic regression with incomplete (biochemical/ structural) response to initial therapy as the response variable. This higher than usual level of significance (0.15) was used to minimize the risk of neglecting important variables for the outcome. ROC (receiveroperating characteristic) curves were constructed for the $\mathrm{I}^{\text {st }} \mathrm{STg}$ and STg/TSH ratio to establish cutoffs which could predict incomplete therapeutic (biochemical/ structural) response, with respective area under the curve (AUC), sensitivity, specificity, positive predictive value (PPV), negative predictive value (NPV) and accuracy. Considering these cutoffs, Kaplan-Meyer curves were also constructed to evaluate survival time in excellent/ indeterminate response. 


\section{RESULTS}

Clinical, histopathological, therapeutic, and evolution data of the studied cases can be found in Table 1. The majority $(\mathrm{n}=158 ; 87.3 \%)$ were female and declared race white $(\mathrm{n}=169 ; 93.4 \%)$. Seventy-five patients $(41.4 \%)$ were submitted to lymph node dissection. The most frequent histological type was CP $(\mathrm{n}=163$; $90.1 \%)$, with 117 cases (64.6\%) having presented TNM Stage I and $99(54.7 \%)$ displaying low risk of recurrence. The majority of cases $(\mathrm{n}=170 ; 94.4 \%)$ presented positive at $1^{\text {st }} \mathrm{WBS}$, and of these most had only had neck uptake $(\mathrm{n}=163 ; 95.9 \%)$. Accumulated mean DTI [ \pm standard deviation (SD)] was 158.77 $( \pm 56.92) \mathrm{mCi}$. Mean $( \pm \mathrm{SD})$ values of $\mathrm{I}^{\text {st }} \mathrm{STg}$ and $\mathrm{STg} / \mathrm{TSH}$ ratio were $35.11( \pm 245.29) \mathrm{ng} / \mathrm{mL}$ and $0.47( \pm 3.28)$, respectively. One hundred and sixteen patients $(64.1 \%)$ presented an excellent response l year after initial treatment, while 120 (66.3\%) presented this same response at final evaluation, with a mean $( \pm$ SD $)$ follow-up time of $87.24( \pm 44.94)$ months $($ median $=76$, minimum $=24$, maximum $=$ 188 months). Twenty-eight cases (15.5\%) presented incomplete (biochemical or structural) response at some time during follow-up.

Cases with incomplete (biochemical or structural) response at final evaluation were compared with those with excellent/indeterminate response (Table 2), with the former group displaying higher serum concentrations of $1^{\text {st }}$ STg $[225.13 \pm 585.26$ $\mathrm{ng} / \mathrm{mL}$ versus (vs) $20.4 \pm 192.9 \mathrm{ng} / \mathrm{mL} ; \mathrm{p}<0.001]$ and $\mathrm{STg} / \mathrm{TSH}$ ratio $(3.01 \pm 7.8$ vs $0.27 \pm 2.58$; $\mathrm{p}<$ $0.001)$. The patients with incomplete response also presented a higher percentage of cases of high risk of recurrence $(38.5 \%$ vs $14.9 \% ; \mathrm{p}=0.078)$ and received higher accumulated doses of ${ }^{131} \mathrm{I}(383.8 \pm 286.6 \mathrm{mCi}$ vs $168.02 \pm 86.51 \mathrm{mCi} ; \mathrm{p}<0.0001)$. The groups did not differ in the other evaluated parameters.

In the multivariate analysis, performed with variables where $p \leq 0.15$, the type of cancer [for FC; odds ratio $(\mathrm{OR})=5.552 ;$ confidence interval $(\mathrm{CI}): 1.082-28.5 ; \mathrm{p}$ $=0.04]$ and accumulated DTI $(\mathrm{OR}=1.008$; CI: $1.003-$ $1.013 ; \mathrm{p}=0.001)$ continued as significant.

ROC curves were constructed to establish cutoff points for $1^{\text {st }} S \mathrm{Tg}$ and $\mathrm{STg} / \mathrm{TSH}$ values that could predict a higher risk of the patient presenting incomplete response at last evaluation (Figure 1). The cutoff obtained for $1^{\text {st }} S T g$ was $5 \mathrm{ng} / \mathrm{mL}$, with AUC of 0.907 (p < 0.001; CI 95\%: 0.84-0.97), 76.7\% sensitivity, 79.2\% specificity, 22.2\% VPP, 97.8\% VPN and $79 \%$ accuracy. For the $\mathrm{STg} / \mathrm{TSH}$ ratio cutoff was 0.085 , with AUC of 0.920 ( $\mathrm{p}<0.001$; CI 95\%: 0.870.97 ), $76.9 \%$ sensitivity, $82.6 \%$ specificity, $25.6 \%$ VPP, $97.8 \%$ VPN and $82.2 \%$ accuracy.

Table 1. Clinical, histopathological, therapeutic, and evolutionary data of the studied population

\begin{tabular}{|c|c|}
\hline \multicolumn{2}{|l|}{ Data } \\
\hline Female, $n(\%)^{\mathrm{a}}$ & $158(87.3)$ \\
\hline White color reported, n (\%) ${ }^{\mathrm{a}}$ & $169(93.4)$ \\
\hline Age (years) ${ }^{b}$ & $48.45 \pm 14.19$ \\
\hline Lymph node dissection, $\mathrm{n}(\%)^{\mathrm{a}}$ & $75(41.4)$ \\
\hline \multicolumn{2}{|l|}{ Type of cancer } \\
\hline Papillary carcinoma, n (\%) ${ }^{\mathrm{a}}$ & $163(90.1)$ \\
\hline Classical variant, $\mathrm{n}(\%)^{\mathrm{a}}$ & $101(62.0)$ \\
\hline Follicular variant, $\mathrm{n}(\%)^{\mathrm{a}}$ & $51(31.3)$ \\
\hline Oncocytic variant, $\mathrm{n}(\%)^{\mathrm{a}}$ & $6(3.7)$ \\
\hline Sclerosing variant, $\mathrm{n}(\%)^{\mathrm{a}}$ & $2(1.2)$ \\
\hline Solid variant, $\mathrm{n}(\%)^{\mathrm{a}}$ & $3(1.8)$ \\
\hline Follicular carcinoma, n (\%) ${ }^{\mathrm{a}}$ & $18(9.9)$ \\
\hline \multicolumn{2}{|l|}{ Staging (TNM) } \\
\hline I, n (\%) ${ }^{\mathrm{a}}$ & $117(64.6)$ \\
\hline$\|, n(\%)^{a}$ & $25(13.8)$ \\
\hline III, n (\%) $)^{\mathrm{a}}$ & $24(13.3)$ \\
\hline IV, n (\%) & $15(8.3)$ \\
\hline \multicolumn{2}{|l|}{ Risk of recurrence } \\
\hline Low, n (\%) & $99(54.7)$ \\
\hline Intermediate, $\mathrm{n}(\%)^{\mathrm{a}}$ & $52(28.8)$ \\
\hline High, n (\%) ${ }^{\mathrm{a}}$ & 30 (16.6) \\
\hline Positive 1st WBS, n (\%) ${ }^{\mathrm{a}}$ & $170(94.4)$ \\
\hline Cervical uptake, $\mathrm{n}(\%)^{\mathrm{a}}$ & $163(95.9)$ \\
\hline Cervical and distant uptake, $\mathrm{n}(\%)^{\mathrm{a}}$ & $7(4.1)$ \\
\hline RIT total dose $(\mathrm{mCi})^{\mathrm{b}}$ & $158.77 \pm 56.92$ \\
\hline $1^{\text {st }} \mathrm{STg}(\mathrm{ng} / \mathrm{mL})^{\mathrm{b}}$ & $35.11 \pm 245.29$ \\
\hline STg/TSH ratio ${ }^{\text {b }}$ & $0.47 \pm 3.28$ \\
\hline \multicolumn{2}{|l|}{ Therapeutic response in one year } \\
\hline Excellent, $n(\%)^{\mathrm{a}}$ & $116(64.1)$ \\
\hline Indeterminate, $\mathrm{n}(\%)^{\mathrm{a}}$ & $50(27.6)$ \\
\hline Incomplete biochemistry, $\mathrm{n}(\%)^{\mathrm{a}}$ & $3(1.7)$ \\
\hline Incomplete structural, $\mathrm{n}(\%)^{\mathrm{a}}$ & $12(6.6)$ \\
\hline Incomplete response at some point, $\mathrm{n}(\%)^{\mathrm{a}}$ & $28(15.5)$ \\
\hline \multicolumn{2}{|l|}{ Therapeutic response in the last evaluation } \\
\hline Excellent, $n(\%)^{a}$ & $120(66.3)$ \\
\hline Indeterminate, $\mathrm{n}(\%)^{\mathrm{a}}$ & $48(26.5)$ \\
\hline Incomplete biochemistry, $\mathrm{n}(\%)^{\mathrm{a}}$ & $3(1.7)$ \\
\hline Incomplete structural, n (\%) ${ }^{\mathrm{a}}$ & $10(5.5)$ \\
\hline Follow-up time (months) ${ }^{b}$ & $87.24 \pm 44.96$ \\
\hline
\end{tabular}

$1^{\text {st }}$ STg: first stimulated thyroglobulin; mCi: milicuries; n: number; \%: percentage; RTI: radioactive iodine ablation/therapy; TNM: American Joint Commission on Cancer (AJCC) tumor staging system; TSH: thyrotropin; WBS: whole-body scan.

${ }^{a}$ Frequencies and percentages for categorical variables.

${ }^{\mathrm{b}}$ Mean \pm standard deviation. 
Table 2. Comparison between patients with excellent/indeterminate and incomplete response (biochemical and/or structural) in the last evaluation, regarding clinical, laboratory, histopathological, and therapeutic data

\begin{tabular}{|c|c|c|c|}
\hline \multirow[b]{2}{*}{ Data } & \multicolumn{2}{|c|}{ Response } & \multirow[b]{2}{*}{$\mathbf{P}$} \\
\hline & $\begin{array}{l}\text { Excellent/Indeterminate } \\
\quad n=168(92.8 \%)\end{array}$ & $\begin{array}{l}\text { Incomplete (Biochemical/Structural) } \\
\qquad n=13(7.2 \%)\end{array}$ & \\
\hline Female, $n(\%)^{a}$ & $146(86.9)$ & 12 (92.3) & 0.573 \\
\hline Age (years) ${ }^{b}$ & $48.24 \pm 13.75$ & $51.15 \pm 19.48$ & 0.476 \\
\hline Lymph node dissection, $\mathrm{n}(\%)^{\mathrm{a}}$ & $68(40.5)$ & $7(53.8)$ & 0.345 \\
\hline Type of cancer & & & 0.100 \\
\hline Papillary carcinoma, n (\%) & $153(91.1)$ & $10(76.9)$ & \\
\hline Follicular carcinoma, n (\%) & $15(8.9)$ & $3(23.1)$ & \\
\hline Staging (TNM) & & & 0.230 \\
\hline I, n (\%) ${ }^{\mathrm{a}}$ & $110(65.5)$ & $7(53.8)$ & \\
\hline$\|, n(\%)^{a}$ & $23(13.7)$ & $2(15.4)$ & \\
\hline III, n (\%) $)^{\mathrm{a}}$ & $23(13.7)$ & $1(7.7)$ & \\
\hline IV, n (\%) $)^{\mathrm{a}}$ & $12(7.1)$ & $3(23.1)$ & \\
\hline Risk of recurrence & & & 0.078 \\
\hline Low, n (\%) & $93(55.4)$ & $6(46.1)$ & \\
\hline Intermediate, $\mathrm{n}(\%)^{\mathrm{a}}$ & $50(29.8)$ & $2(15,4)$ & \\
\hline High, n (\%) ${ }^{\mathrm{a}}$ & $25(14.9)$ & $5(38.5)$ & \\
\hline Positive 1st WBS, n (\%) & $157(94)$ & $13(100)$ & 1.00 \\
\hline RIT total dose $(\mathrm{mCi})^{\mathrm{b}}$ & $168.02 \pm 86.51$ & $383.8 \pm 286.6$ & $<0.0001$ \\
\hline $1^{\text {st }} \mathrm{STg}(\mathrm{ng} / \mathrm{mL})^{\mathrm{b}}$ & $20.4 \pm 192.9$ & $225.13 \pm 585.26$ & $<0.001$ \\
\hline STg/TSH ratio ${ }^{b}$ & $0.27 \pm 2.58$ & $3.01 \pm 7.8$ & $<0.001$ \\
\hline Follow-up time (months) ${ }^{b}$ & $88.16 \pm 45.36$ & $75.38 \pm 39.06$ & 0.325 \\
\hline
\end{tabular}

$1^{\text {st }}$ STg: first stimulated thyroglobulin; mCi: milicuries; n: number; \%: percentage; RTI: radioactive iodine ablation/therapy; TNM: American Joint Commission on Cancer (AJCC) tumor staging system; TSH: thyrotropin; WBS: whole-body scan.

a Frequencies and percentages; Chi-square and Fisher's exact tests.

${ }^{\mathrm{b}}$ Mean \pm standard deviation; Student's t-test. Statistical significance: $p<0,05$.
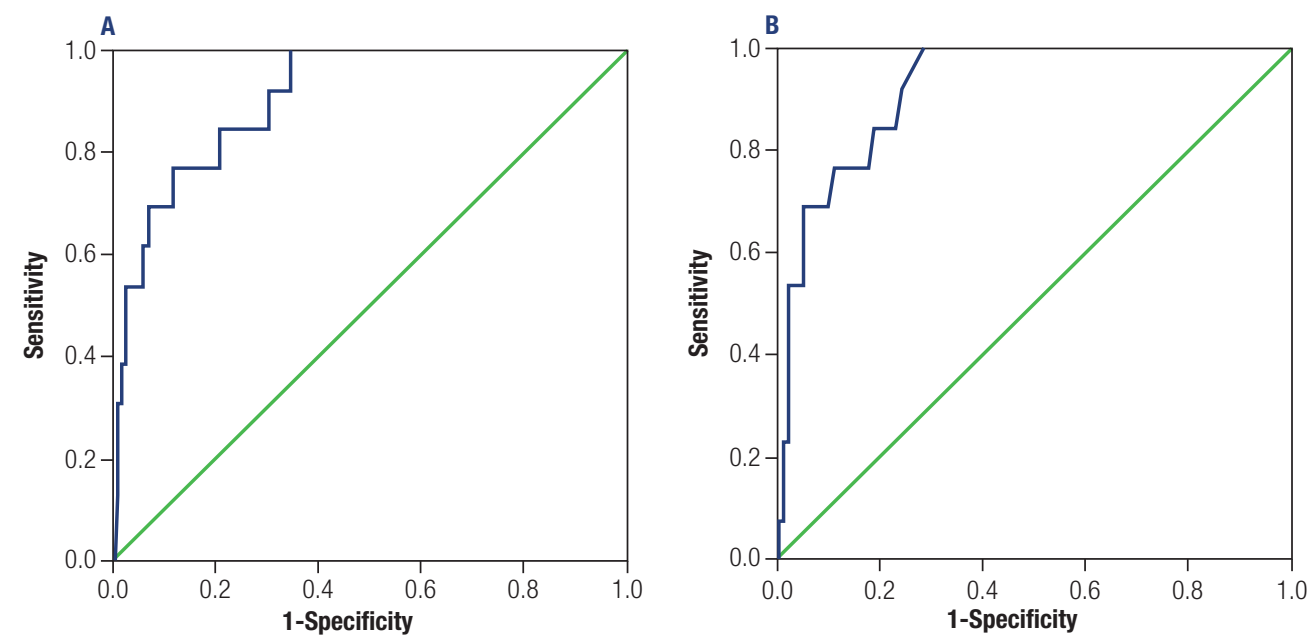

Figure 1. Receiver-operating characteristic (ROC) curves of the first stimulated thyroglobulin $[A$ : cutoff $=5.0 \mathrm{ng} / \mathrm{mL} \mathrm{ng} / \mathrm{mL}$ (area under the curve: 0.907 ; $p<0.001$ )] and regarding first stimulated thyroglobulin/thyroid-stimulating hormone ratio [B: cutoff $=0.085$ (area under the curve: $0.920 ; p<0.001$ )] as predictors of incomplete response (biochemical and/or structural) in the last evaluation.

The cases with $1^{\text {st }} \mathrm{TgS} \geq 5 \mathrm{ng} / \mathrm{mL}$ showed survival maintained in an excellent/indeterminate response for an average time of 15.9 months, whereas in those with $1^{\text {st }} \mathrm{Tg}<5 \mathrm{ng} / \mathrm{mL}$, this time was 140.4 months.
In patients with $\mathrm{STg} / \mathrm{TSH}$ ratio $\geq 0.085$, this time was 15.9 months against 144.6 months in those with STg/ TSH ratio $<0.085$ (Figure 2). 

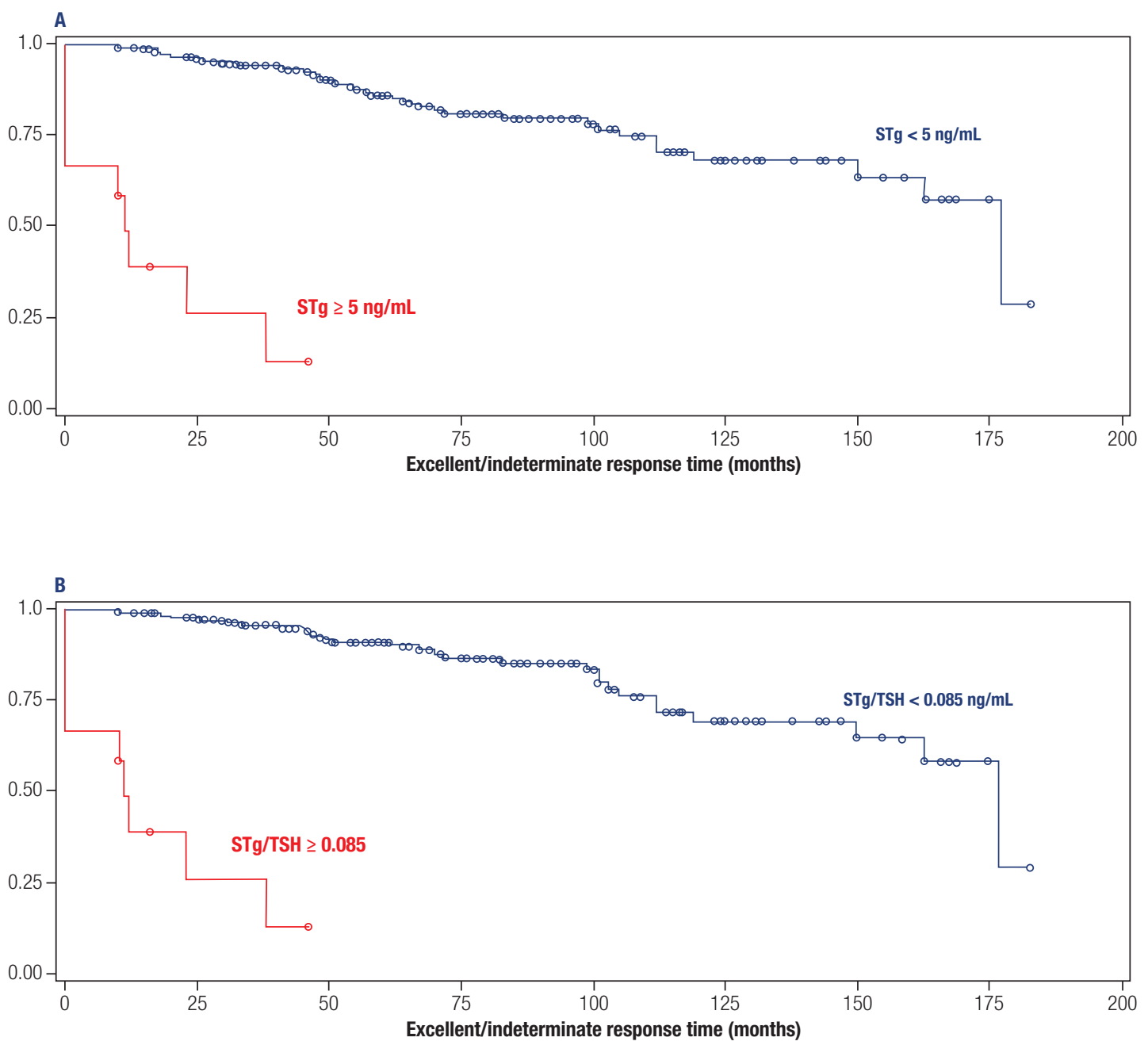

Figure 2. Kaplan-Meyer curves to assess patient survival time in excellent/indeterminate response, using the cutoff point established for the first stimulated thyroglobulin - STg as variable (A: mean survival with STg $\geq 5 \mathrm{ng} / \mathrm{mL}=15.9$ months and with STg $<5 \mathrm{ng} / \mathrm{mL}=140.4 \mathrm{months}$; Log Rank $<0.001$ ) and for the first stimulated thyroglobulin/thyrotrophin $-\mathrm{STg} / \mathrm{TSH}$ ratio (B: mean survival with STg/TSH $\geq 0.085=15.9$ months and with STg/ $\mathrm{TSH}<0.085=144.6$ months; Log Rank $<0.001$ ) in the last evaluation as predictors of outcome.

\section{DISCUSSION}

In this study we demonstrated that both $\mathrm{I}^{\text {st }} \mathrm{STg}$ and the STg/TSH ratio, evaluated 1-3 months after TT and before $\mathrm{l}^{\text {st }}$ DTI, showed an association with long-term prognosis for DTC. Tg, and particularly STg, is already recognised as a prognosis and remission marker for the disease (17). However, as it is influenced by TSH level, it is interesting to evaluate the $\mathrm{STg} / \mathrm{TSH}$ ratio, which has been associated with metastases detection and DTI effectiveness $(11,15,19)$, but not until the completion of this study, had its potential in long-term prognosis been assessed.

In this study, after a mean follow-up time of 87 months, patients with excellent/indeterminate response at final consultation presented $\mathrm{l}^{\text {st }} \mathrm{STg}$ lower than cases with incomplete (biochemical/structural) response. Concentrations equal or greater than $5 \mathrm{ng} / \mathrm{mL}$ were predictors of incomplete response at final consultation with elevated sensitivity, specificity, VPN, and accuracy (76.7\%, 79.2\%, $97.8 \%$ and $79 \%$, respectively). Only VPP was lower, possibly influenced by the relatively small number of patients with incomplete/indeterminate response. Evaluating intermediate-risk patients, Faro and cols. observed a higher cutoff point for the marker, with STg levels> $10 \mathrm{ng} / \mathrm{mL}$ having been associated with an incomplete response (22). Perhaps the reason for the difference observed could be the time to assess the outcome, which in that study was 12 to 18 months (22). Interestingly, the $1^{\text {st }} S T g$ cutoff value observed in this study was very close to that seen in an earlier 
study by the same service $(4.4 \mathrm{l} \mathrm{ng} / \mathrm{mL})$, and which proved to be a predictor of DTI ablative success (11). STg was also a predictor of maintenance time in response to excellent/indeterminant response during follow-up, where cases with $\mathrm{STg}<5 \mathrm{ng} / \mathrm{mL}$ having presented a time around 8.8 times longer than those where the marker was above this level. In fact, $1^{\text {st }} \mathrm{STg}$ is recognised as a prognosis marker for DTC patients where levels below $1 \mathrm{ng} / \mathrm{mL}$ have been associated with absence of structural disease with prediction rates over $90 \%$ (7). However, the capacity of $1^{\text {st }} \mathrm{STg}$ in predicting long-term disease absence has been variable, with VPNs between $69.8 \%$ and $94.2 \%$ having been reported $(7,23)$. As for the association between $\mathrm{I}^{\text {st }} \mathrm{STg}$ and maintenance time in excellent response, this has generally not been a focal point in different studies thus making comparison difficult.

As already cited, despite its excellent performance, STg can be influenced by TSH level. In fact, although patients with excellent or incomplete response do not seem to significantly differ in terms of STg levels, when these are obtained with TSH values between 30-60 mU/L, higher concentrations of the pituitary hormone can cause more significant elevations in the marker, providing differentiation between these groups (18). It is true that, with the advent of recombinant TSH, this discussion could seem to be without reason. However, this is not yet widely available to the general population, and significant numbers of patients, especially those monitored in the public health service, still depend on endogenous TSH elevation for performing STg measurements. A limiting factor in this approach is that the achievement of much higher endogenous TSH levels generally implies the absence of levothyroxine treatment for long periods, which in turn can lead to a higher incidence of adverse effects and impact quality of life (24-26). In this context, correcting the marker by TSH concentration at time of evaluation, which occurs when using the STg/ TSH ratio, seems more appropriate. In this study, we observed that patients with incomplete response at final evaluation had presented much higher values of this ratio soon after initial treatment. Values equal to or greater than 0.085 have even been shown as predictors of incomplete response, with high sensitivity, specificity, VPN and accuracy $(76.9 \%, 82.6 \%, 97.8 \%$ and $82.2 \%$, respectively). As with STg, only PPV was low. This cutoff value was very close to that seen in a previous study at the same service $(0.093)$ which proved to be a predictor of DTI ablative success (11). However, it was much lower than the value reported by other authors who also evaluated ablative success (19). In our study, this ratio was also a predictor of maintenance time in excellent/indeterminate response during follow-up, with cases presenting an STg/TSH ratio $<0.085$ having an around 9 times longer maintenance time than those where the ratio value was higher. No studies were found evaluating $\mathrm{STg} / \mathrm{TSH}$ ratio regarding maintenance time in a given response.

This study has limitations, such as its retrospective character and the not very large sample number, particularly in relation to incomplete response cases, which could have contributed the findings obtained in analysis of association not being maintained in multivariate analysis, for instance reduced VPP seen for STg and STG/TSH ratio cutoffs. However, this study has merit in presenting the $\mathrm{STg} / \mathrm{TSH}$ ratio as an additional tool for predicting long-term prognosis, considering response outcome to initial therapy in the light of the most recent recommendations for monitoring DTC. This ratio could be particularly useful in situations where the increase obtained in endogenous TSH has not been so significant.

In conclusion, our results indicate that the STg/ TSH ratio has a similar performance to the $1^{\text {st }} S \mathrm{Tg}$ in predicting long-term response to initial therapy. Thus, these are both useful markers in evaluating prognosis for DTC patients. More studies with larger samples are necessary to investigate the real role of the STg/TSH ratio in following up these patients.

Acknowledgements: the authors a very grateful to Eloisa Elena Paschoalinotte, from Research Support Office (EAP) - Botucatu Medical School - Unesp, for statistical analysis.

Contributions: all authors contributed to this manuscript.

Disclosure: no potential conflict of interest relevant to this article was reported.

\section{REFERENCES}

1. Veiga LH, Neta G, Aschebrook-Kilfoy B, Ron E, Devesa SS.Thyroid cancer incidence patterns in Sao Paulo, Brazil, and the U.S. SEER program, 1997-2008. Thyroid. 2013;23(6):748-57.

2. Haugen BR, Alexander EK, Bible KC, Doherty GM, Mandel SJ, Nikiforov YE, et al. 2015 American Thyroid Association Management Guidelines for Adult Patients with Thyroid Nodules and Differentiated Thyroid Cancer: The American Thyroid Association Guidelines Task Force on Thyroid Nodules and Differentiated Thyroid Cancer. Thyroid. 2016;26(1):1-133. 
3. da Silva MA, Valgôde FG, Gonzalez JA, Yoriyaz H, Guimarães MI, Ribela MT, et al. Cytogenetic and dosimetric effects of (131) I in patients with differentiated thyroid carcinoma: comparison between stimulation with rhTSH and thyroid hormone withdrawal treatments. Radiat Environ Biophys. 2016;55(3):317-28.

4. Van Dijk D, Plukker JTM, van der Horst-Schrivers ANA, Jansen $\mathrm{L}$, Brouwers AH, Muller-Kobold A, et al. The value of detectable thyroglobulin in patients with differentiated thyroid cancer after initial 131I therapy. Clin Endocrinol. 2011;74(1):104,10.

5. Kim MH, Ko SH, Bae JS, Lim DJ, Baek KH, Lee JM, et al. Combination of initial stimulation thyroglobulins and staging system by revised ATA guidelines can elaborately discriminate prognosis of patients with differentiated thyroid carcinoma after high-dose remnant ablation. Clin Nucl Med. 2012;37(11):1069-74.

6. Dewi AR, Darmawan B, Kartamihadja AH, Hidayat B, Masjhur JS. Antithyroglobulin Antibody as a Marker of Successful Ablation Therapy in Differentiated Thyroid Cancer. World J Nucl Med. 2017;16(1):15-20.

7. Liang J, Li T, Lin Y, Yang X, Zhao T. Preablative stimulated thyroglobulin correlates to new therapy response system in differentiated thyroid cancer. J Clin Endocrinol Metab. 2016;101(3):1307-13.

8. Gadawska-Juszczyk K, Kowalska A. Comparison of the usefulness of post-ablative and postperative thyroglobulin concentration measuring in prognostic assessment of patients with differentiated thyroid cancer. Endokrynol Pol. 2015;66(6):486-94.

9. Sugitani I, FujimotoY. Does postoperative thyrotropin suppression therapy truly decrease recurrence in papillary thyroid carcinoma? A randomized controlled trial. J Clin Endocrinol Metab. 2010;95(10):4576-83.

10. Do Cao C, Wémeau JL. Risk-benefit ratio for TSH-suppressive Levothyroxine therapy in differentiated thyroid cancer. Ann Endocrinol. 2015;76(1 Suppl 1):1S47-52.

11. Trevizam PG, Tagliarini JV, Castilho EC, de Alencar Marques M, Kiy Y, da Silva Mazeto GM. Thyroglobulin levels and thyroglobulin/ thyrotropin ratio could predict the success of the ablative/ therapeutic $131 \mathrm{l}$ in the differentiated thyroid cancers. Endocr Res. 2017;42(1):42-8.

12. Amui IO, Tagliarini JV, Castilho EC, Marques MA, Kiy Y, Corrente $\mathrm{JE}$, et al. The first postoperative-stimulated serum thyroglobulin is a prognostic factor for thyroid microcarcinomas. Braz $\mathrm{J}$ Otorhinolaryngol. 2019;85(1):37-42.

13. Rosario PW, Carvalho M, Mourao GF, Calsolari MR. Comparison of Antithyroglobulin Antibody Concentrations Before and After Ablation with 1311 as a Predictor of Structural Disease in Differentiated Thyroid Carcinoma Patients with Undetectable Basal Thyroglobulin and Negative Neck Ultrasonography. Thyroid. 2016;26(4):525-31.

14. Kuo SF, Chao TC, Chang HY, Hsueh C, Lin CL, Chiang KC, et al. Prognosis of papillary thyroid cancers with positive serum thyroglobulin antibody after total thyroidectomy. Asian J Surg. 2017;40(3):186-92.

15. Lin Y, LiT, Liang J, Qiu L, Wang S, ChenY, et al. Predictive value of preablation stimulated thyroglobulin and thyroglobulin/thyroid- stimulating hormone ratio in differentiated thyroid cancer. Clin Nucl Med. 2011;36(12):1102-5.

16. Polachek A, Hirsch D, Tzvetov G, Grozinsky-Glasberg S, Slutski I, Singer J, et al. Prognostic value of post-thyroidectomy thyroglobulin levels in patients with differentiated thyroid cancer. J Endocrinol Invest. 2011;34(11):855-60.

17. Rosario PW, Mineiro Filho AF, Lacerda RX, dos Santos DA, Calsolari MR. The value of diagnostic whole-body scanning and serum thyroglobulin in the presence of elevated serum thyrotropin during follow-up of anti-thyroglobulin antibody-positive patients with differentiated thyroid carcinoma who appeared to be free of disease after total thyroidectomy and radioactive iodine ablation. Thyroid. 2012;22(2):113-6.

18. Zhao T, Liang J, Guo Z, Li J, Lin Y. Serum thyrotropin level of 30 $\mu \mathrm{lU} / \mathrm{mL}$ is inadequate for preablative thyroglobulin to serve as a prognostic marker for differentiated thyroid cancer. Endocrine. 2016;53(1):166-73.

19. Hussain SZ, Zaman M, Malik S, Ram N, Asghar A, Rabbani U, et al. Preablation stimulated thyroglobulin/TSH ratio as a predictor of successful I(131)remnant ablation in patients with differentiated thyroid cancer following total thyroidectomy. J Thyroid Res. 2014;2014:610273.

20. DeLellis RA, Lloyd RV, Heitz PU, Eng C. World Health Organization classification of tumors: pathology and genetics of tumors of endocrine organs. Lyon: IARC Scientific Publications; 2004.

21. Edge SB, Byrd DR, Compton CC, Fritz AG, Greene FL, Trotti A. Thyroid. In: Edge SB, Byrd DR, Compton CC, Fritz AG, Greene FL, Trotti A, editors. AJCC Cancer Staging Manual. 7th ed. New York: Springer; 2010. p. 87-96.

22. Faro FN, Bezerra ÂMLB, Scalissi NM, Cury AN, Marone MM, Ferraz $C$, et al. Intermediate-risk thyroid carcinoma: indicators of a poor prognosis. Arch Endocrinol Metab. 2020 Aug 28;S235939972020005006213. doi: 10.20945/2359-3997000000290. Online ahead of print.

23. Webb RC, Howard RS, Stojadinovic A, Gaitonde DY, Wallace MK, Ahmed J, et al. The utility of serum thyroglobulin measurement at the time of remnant ablation for predicting disease-free status in patients with differentiated thyroid cancer: a meta-analysis involving 3947 patients. J Clin Endocrinol Metab. 2012;97(8):2754-63.

24. Borget I, Remy H, Chevalier J, Ricard M, Allyn M, Schlumberger $M$, et al. Length and cost of hospital stay of radioiodine ablation in thyroid cancer patients: comparison between preparation with thyroid hormone withdrawal and thyrogen. Eur J Nucl Med Mol Imaging. 2008;35(8):1457-63.

25. Rosario PW, Borges MAR, Purisch S. Preparation with recombinant human thyroid-stimulating hormone for thyroid remnant ablation with 131 I is associated with lowered radiotoxicity. J Nucl Med. 2008; 49(11):1776-82

26. Haugen BR, Pacini F, Reiners C, Schlumberger M, Ladenson PW, Sherman SI, et al. A comparison of recombinant human thyrotropin and thyroid hormone withdrawal for the detection of thyroid remnant or cancer. J Clin Endocrinol Metab. $1999 ; 84(11): 3877-85$. 